\title{
Climate impacts on agricultural land use in the USA: the role of socio-economic scenarios
}

\author{
Jianhong E. Mu ${ }^{1} \cdot$ Benjamin M. Sleeter ${ }^{2}$. \\ John T. Abatzoglou ${ }^{3}$ • John M. Antle ${ }^{4}$
}

Received: 12 September 2016 / Accepted: 18 July 2017 / Published online: 9 August 2017

(C) The Author(s) 2017. This article is an open access publication

\begin{abstract}
We examine the impacts of climate on net returns from crop and livestock production and the resulting impact on land-use change across the contiguous USA. We first estimate an econometric model to project effects of weather fluctuations on crop and livestock net returns and then use a semi-reduced form land-use share model to study agricultural land-use changes under future climate and socio-economic scenarios. Estimation results show that crop net returns are more sensitive to thermal and less sensitive to moisture variability than livestock net returns; other agricultural land uses substitute cropland use when 30-year averaged degree-days or precipitation are not beneficial for crop production. Under future climate and socio-economic scenarios, we project that crop and livestock net returns are both increasing, but with crop net returns increasing at a higher rate; cropland increases with declines of marginal and pastureland by the end of the twenty-first century. Projections also show that impacts of future climate on agricultural land uses are substantially different and a larger variation of land-use change is evident when socio-economic scenarios are incorporated into the climate impact analysis.
\end{abstract}

Electronic supplementary material The online version of this article (doi:10.1007/s10584-017-2033-x) contains supplementary material, which is available to authorized users.

Jianhong E. Mu

mujh1024@gmail.com

1 Department of Geography and Environmental Sustainability, University of Oklahoma, Norman, OK 73019, USA

2 Western Geographic Science Center, U.S. Geological Survey, Menlo Park, CA 94025, USA

3 Department of Geography, University of Idaho, Moscow, ID 83844, USA

4 Department of Applied Economics, Oregon State University, Corvallis, OR 97330, USA 


\section{Introduction}

Agriculture is a climate-sensitive sector that must adapt to climate change to maintain its economic vitality and meet the increasing caloric demands of a growing population. This also means that understanding the potential for agricultural adaptation, and how it could come about, is important for ongoing technology investments in the public and private sectors, for infrastructure investments, and for the various policies that address agriculture directly or indirectly (Antle and Capalbo 2010).

Previous literature has examined impacts of future climate on agriculture with statistical "reduced-form" models that embody adaptation implicitly (Burke et al. 2015, Deschênes and Greenstone 2007, 2012, Fezzi and Bateman 2015, Kelly et al. 2005, Mendelsohn et al. 1994, Mu et al. 2013) or in "structural" models that represent adaptation explicitly (Adams et al. 1990, Antle et al. 2004, Mu et al. 2015, Reilly et al. 2003). A key limitation of these studies is that they project impacts of climate change and adaptation under the assumption of no change in future socioeconomic environment. The goal of this paper is to investigate whether farmers' adaptation behavior could be different under future climate when incorporating future socio-economic scenarios into the analysis. To address this question, we use a two-stage approach to directly incorporate impacts of socio-economic variables. In the first stage, we apply a hedonic model to examine impacts of weather fluctuations on crop or livestock net returns given that crop and livestock production have different responses to annual weather effects. In the second stage, we estimate a semi-reduced form land-use model that assumes farmers make land-use decisions based on expected market returns. We then combine the two stages to project changes in land use using projections of future climate and future agricultural land-use net returns.

One advantage of the semi-reduced form land-use model is that model parameters are the combination of the structural land-use model's parameters. It is not a fully reduced form in the sense that some of the explanatory variables (net returns) could themselves be functions of weather and other variables. Thus, this model has an important feature of structural form models that can account for economic responses to climate effects. This feature allows us to assess climate impacts under future socio-economic scenarios that are consistent with the future climate projections that are used. This approach contrasts with previous studies that combined projections of future climate with statistically estimated models that embody current or historical socio-economic conditions to model crop yields, economic returns, or land values (Deschênes and Greenstone 2007, Mendelsohn et al. 1994, Schlenker et al. 2005) as well as land use (Haim et al. 2011, Lawler et al. 2014, Lubowski et al. 2006, 2008, Mu et al. 2013, Radeloff et al. 2012, Wu et al. 2004).

\section{Methods}

A two-stage approach is used in this paper. In the first stage, we follow Deschênes and Greenstone (2007) to estimate a hedonic model of crop or livestock net returns:

$$
R S_{c t}^{h}=\alpha_{c}+\gamma_{t}+Y_{c t}^{\prime} \delta+W_{c t}^{\prime} \omega+\varepsilon_{c t}
$$

where $R S_{c t}^{h}$ is the land-use net return in county $c$ at year $t$ for $h=$ crop or livestock, and the unit is dollar per acre in 2010 value. $\alpha_{c}$ and $\gamma_{t}$ are a full set of county and year fixed 
effects, respectively. $Y_{c t}$ is a vector of non-climate variables, including per capita income, population density, irrigation rate and soil conditions. The variables of interest are the weather fluctuations variables, $W_{c t}$, which include growing season precipitation and degree-days, precipitation intensity index and drought index. $\varepsilon_{c t}$ is the error term.

Using estimated coefficients from Eq. (1), we predict land-use net returns for crop and livestock production and incorporate them into the semi-reduced form land-use share model:

$$
\theta_{i c t}=\theta_{i}\left(\Gamma_{c t}, S_{c t}, R_{c t}, Z_{c t}\right)
$$

where $\theta_{i c t}$ is the land-use share for system $i$ in county $c$ at year $t . i$ includes cropland, marginal land, pastureland, and woodland. $\Gamma_{c t}$ represents expected climate conditions, including 30 -year averaged precipitation and degree-days. $S_{c t}$ is soil conditions; $R_{c t}$ includes annualized government payments and net returns from crop and livestock production. $Z_{c t}$ includes other variables, such as population density, irrigation rate and time trend. We include population density in both the land use and the hedonic model as more population means an increase in demand for agricultural goods, which has direct and indirect effects on land use.

In an econometric context, the conditional mean model for land-use share $i$ is assumed to be $E\left[\theta_{i c t} \mid X\right]=G_{i}(\beta, X)$, where $\beta$ s are parameters to be estimated and $X$ is a vector of explanatory variables as in Eq. (2). Constraints of $\theta$ include $\theta_{i c t} \in[0,1]$ and $\sum_{i} \theta_{i c t}=1$. With a multinomial logit functional form for $G_{i}(\beta, X)$, the conditional distribution of agricultural land shares among $i$ is given as,

$$
E\left[\theta_{i t} \mid X\right]=\frac{\exp \left(X^{\prime} \beta_{i}\right)}{\sum_{i=1}^{I} \exp \left(X^{\prime} \beta_{i}\right)} \text { for } i=1,2, \ldots, I
$$

Equation (3) may be biased due to possible unobservables in the error term that may be correlated with annualized net returns. For example, farmers' storage plans will affect crop revenue or changes in farm policies also affect farmers' revenue from crop and livestock production. Also the share of land with irrigation could be affected by unobservable factors that also affect land allocation. To solve the possible bias problem, we apply the extended Chamberlain-Mundlak approach by assuming that some explanatory variables are correlated with the unobservables (Wooldridge 2009). Following Wooldridge (2009), we estimate a fractional multinomial logit model with correlated random effects. Therefore, the fixed effects estimator can be computed as a pooled estimator using the original data, but adding the time averages of the covariates as additional explanatory variables (Wooldridge 2009).

\section{Data, variables and shared socio-economic pathways}

In this section, we introduce variables and sources of data. We used county annual level data from 1978 to 2012 and Table 1 shows summary statistics for the variables used in the analysis.

\subsection{Agricultural land use and production}

We obtained agricultural land use data from the US Census of Agriculture, which reports county-level agricultural statistics every 5 years since 1982 . To avoid double counting, we reclassified original land use data in four categories: cropland, marginal land, pastureland, 
Table 1 Variable descriptions and summary statistics

\begin{tabular}{|c|c|c|c|c|}
\hline & Mean & Std. Dev. & Min & Max \\
\hline \multicolumn{5}{|c|}{ Variables used in the hedonic model (averages over 1969 to 2011 without gaps) } \\
\hline Crop net return/acre $(2010 \text { dollars })^{\mathrm{a}}$ & 103.38 & 246.91 & -3787.58 & 8837.81 \\
\hline Livestock net return/acre (2010 dollars $)^{a}$ & 60.94 & 103.00 & -629.34 & 3678.82 \\
\hline Growing season precipitation $(10 \mathrm{~cm})$ & 9.92 & 4.04 & 0 & 42.01 \\
\hline Growing season degree-days (1000) & 2.57 & 1.03 & 0 & 6.30 \\
\hline Precipitation intensity index & 0.21 & 0.09 & 0 & 0.67 \\
\hline Drought index & 0.13 & 0.34 & 0.00 & 1 \\
\hline Lagged growing season precipitation & 9.90 & 4.02 & 0 & 42.01 \\
\hline Lagged growing season degree-days & 2.56 & 1.03 & 0 & 6.30 \\
\hline Lagged precipitation intensity index & 0.21 & 0.09 & 0 & 0.67 \\
\hline Real per capita income, thousand 2010 dollars & 24.73 & 12.63 & 3.94 & 151.82 \\
\hline Population density, person per 100 mile $^{2}$ & 1.65 & 11.44 & 0 & 475.60 \\
\hline Irrigation rate & 0.04 & 0.10 & 0 & 1 \\
\hline \multicolumn{5}{|c|}{ Variables used in the semi-reduced land-use model (averages over 1978 to 2012 with 5-year gaps) } \\
\hline Cropland use share & 0.40 & 0.26 & 0.00 & 1 \\
\hline Pastureland use share & 0.38 & 0.27 & 0.00 & 1 \\
\hline Marginal land use share & 0.08 & 0.07 & 0.00 & 1 \\
\hline Woodland use share & 0.13 & 0.14 & 0.00 & 1 \\
\hline Irrigating rate & 0.05 & 0.11 & 0.00 & 1 \\
\hline Annualized crop net return/acre (2010 dollars) ${ }^{\mathrm{b}}$ & 111.81 & 212.89 & -433.27 & 3799.78 \\
\hline Annualized livestock net return/acre (2010 dollars) ${ }^{\mathrm{b}}$ & 65.86 & 87.28 & -173.89 & 1262.18 \\
\hline Annualized government payment/acre $(2010 \text { dollars })^{\mathrm{b}}$ & 8.86 & 12.07 & -102.25 & 471.75 \\
\hline 30 -year average precipitation $(10 \mathrm{~cm})$ & 9.75 & 3.59 & 0.00 & 32.03 \\
\hline 30 -year average degree-days (1000) & 2.56 & 1.02 & 0.00 & 5.98 \\
\hline Drought index & 0.14 & 0.35 & 0.00 & 1.00 \\
\hline Population density, person per 100 miles $^{2}$ & 1.69 & 11.41 & 0.00 & 479.45 \\
\hline Latitude & 38.29 & 4.86 & 25.60 & 48.84 \\
\hline Time trend & 4.50 & 2.29 & 1 & 8 \\
\hline
\end{tabular}

${ }^{a}$ Calculated using imputed land-use and irrigation data from Agricultural Census from 1969 to 2012

${ }^{\mathrm{b}}$ Calculated using 5-year averages of crop and livestock net returns predicted from the hedonic model and are averaged 5 years preceding each Agricultural Census year

and woodland. Cropland includes harvested cropland; marginal land includes cropland for idle, all crops failed, cover crops, summer fallow and land enrolled in conservation reserve, wetlands reserve, farmable wetlands, or conservation reserve enhancement programs; pastureland includes cropland for pasture that could be used for crop production with soil improvement, land used for permanent pasture and rangeland, and woodland mainly for grass and other forage production; woodland is woodland not used for pasture.

We collected data of sales from livestock and crop products, government payments and total production expenses from the US Bureau of Economic Analysis (BEA). We used these data to construct net returns for crop and livestock production as expected system-based profitability following Lubowski et al. (2008). In particular, we calculated per acre crop and livestock net returns by dividing the total cropland, and the total of pastureland and rangeland, respectively. For livestock production, we adjusted livestock net returns by assuming the stocking rate is 0.5 animal units per growing season per acre. ${ }^{1}$ Annualized net returns were calculated over a 5 -year period for 3 years preceding each census year. For example, we used averages over 1999 to 2003 as the annualized net returns for the 2007 census year.

\footnotetext{
${ }^{1}$ The assumption of livestock stocking rate needs additional sensitivity tests because pasture- and rangeland are allocated across the U.S. heterogeneously.
} 
We constructed an index of irrigation management as the proportion of irrigated acres to the total agricultural land to represent the geographic variation of county-level irrigation systems. In addition, we included soil characteristics obtained from the National Resource Inventory (NRI), although they have limited variation across census years. To control demand side effects on net returns and agricultural goods, we included population density and per capita income from the BEA. All dollars were adjusted to 2010 values.

\subsection{Climate data and variables}

Weather fluctuation variables include growing season precipitation measured in $100 \mathrm{~mm}$, growing season degree-days measured in $1000{ }^{\circ} \mathrm{C}$, precipitation intensity, and drought index (Mendelsohn et al. 1994; Schlenker et al. 2006). Precipitation intensity was calculated as a fraction of annual cumulative precipitation that occurred from daily precipitation exceeding the 95th percentile of the climatological distribution for wet days (Tebaldi et al. 2006). Growing season degree-days were calculated using a base threshold of $8^{\circ} \mathrm{C}$ and upper threshold of $32{ }^{\circ} \mathrm{C}$ for each day and summing over the calendar year from January to December. We also constructed a binary measure of drought index when the growing season averaged Palmer Drought Severity Index (PDSI) is less than -2 . Climate variables include 30-year moving average of growing season precipitation and degree-days.

Historical climate observations were obtained by aggregating gridded $\sim 4-\mathrm{km}$ spatial resolution surface meteorological datasets from Abatzoglou (2013) to the county level. For future climater data, we use statistically downscaled climate model simulations for 20 global climate models that took part in the Coupled Model Intercomparison Project Phase 5 (CMIP5). Daily surface meteorological data were statistically downscaled using the Multivariate Adaptive Constructed Analogs method (Abatzoglou and Brown 2012) to 4-km resolution using the observed surface meteorological dataset of Abatzoglou (2013). Downscaling was completed for both historical (1950-2005) and future (2006-2099) model experiments, and considered two Representative Concentration Pathways (RCPs), RCP4.5 and RCP8.5.

\subsection{Future socio-economic scenarios}

Following O’Neill et al. (2015), we extended five future socio-economic pathways (SSPs) to incorporate additional agricultural details. SSP1 describes the world moving towards a more sustainable path, with a combination of directed development of environmentally friendly technologies and relatively low energy demand. SSP2 is a middle of the road pathway that follows historical trends. SSP3 presents a future world with international fragmentation and regional rivalry and conflicts. SSP4 emphasizes increased disparities in economic opportunity, leading to inequality and stratification both across- and within-countries. SPP5 foresees accelerated globalization and rapid development with strong reliance on fossil fuels.

We used projections of population and per capita gross domestic product for the five SSPs from the International Institute for Applied System Analysis. We modified the observed irrigation rates and government payments to be consistent with each SSP narrative. ${ }^{2}$ Specifically, the irrigation rate was assumed to change by $+15 \%$ under SSP $1,-2.5 \%$ under SSP 2 and SSP5 and $-12.5 \%$ under SSP3 and SSP4. Similarly, government payments were assumed to change by $-50 \%$ under SSP $1,+15 \%$ under SSP 2 and SSP 5 , and $-60 \%$ under SSP 3 and SSP 4 .

\footnotetext{
${ }^{2}$ Sensitivity analysis could be used to test the robustness of the assumptions of future trend of irrigation rates and governmental payments.
} 


\section{Results}

\subsection{Impacts of weather fluctuations on agricultural net returns}

Table 2 shows estimation results of the net return model for four specifications: (1) without lagged weather fluctuation variables (column one and five); (2) with weighted regression (column two and six); (3) with lagged weather fluctuation variables (column three and seven); and (4) with weighted regression and lagged weather fluctuation variables (column four and eight). Across the different specifications, we find that crop net returns are more sensitive to growing season degree-days than livestock net returns, particularly for growing season degreedays larger than 2500 degree days. Compared to livestock net returns, crop net returns are less responsive to growing season precipitation, with less value per acre for largest amount of precipitation. By contrast, livestock net returns increase as precipitation amount increases.

Also shown in Table 2, impacts of precipitation intensity index and drought on crop net returns are both significantly negative, while impacts on livestock net returns are statistically insignificant. These effects show that crop net return is more responsive to extreme weather than livestock net returns, implying livestock production is more resilient to drought and intense wet days.

\subsection{Impacts on agricultural land-use shares}

Using predicted values of crop and livestock net returns from the weighted regression with lagged weather fluctuation variables, we then estimated the semi-reduced form land-use share model using Eq. (3). We report marginal effects and the corresponding standard deviations in Table 3 for different land-use shares.

In Table 3, the marginal effects of 30-year averaged precipitation are positive for cropland and negative for marginal and pastureland, while 30-year averaged degree-days have positive effects on crop- and marginal land and insignificant negative effects on pastureland. These results suggest that the between-system competition among agricultural land uses reflects farmers' adaptation response to mean climate. Farmers may increase shares of cropland if they expect future climate would be beneficial for crop production. By contrast, less land is used for grazing. In addition, drought has negative effects on cropland and positive effects on marginal and pastureland. This has two implications. On the one hand, crop growing is sensitive to drought and farmers may suffer from crop failures if drought happens. On the other hand, farmers would put more land into idle, or cover crops, or conservation programs if they expect more frequent droughts.

As predicted by economic theory, estimated results in Table 3 show that farmers' land-use decisions respond to net returns of agricultural production. For example, more land is used for grazing and less land is used for crop when livestock net return is expected to rise or crop net return is expected to decline. In addition, cropland increases and pastureland decreases when government payments go up, implying that farmers would put more low-productivity land into crop production to receive more subsidies or crop and livestock insurance payments. These results appear consistent with research indicating that farmers already enrolled in crop and livestock insurance program do not have the incentive to engage in costly adaptation because insurance compensates them for potential loss (Annan and Schlenker 2015).

Population density affects agricultural land-use allocation to increase crop- and pastureland and reduce marginal land. Increased population density implies higher land values, encouraging 


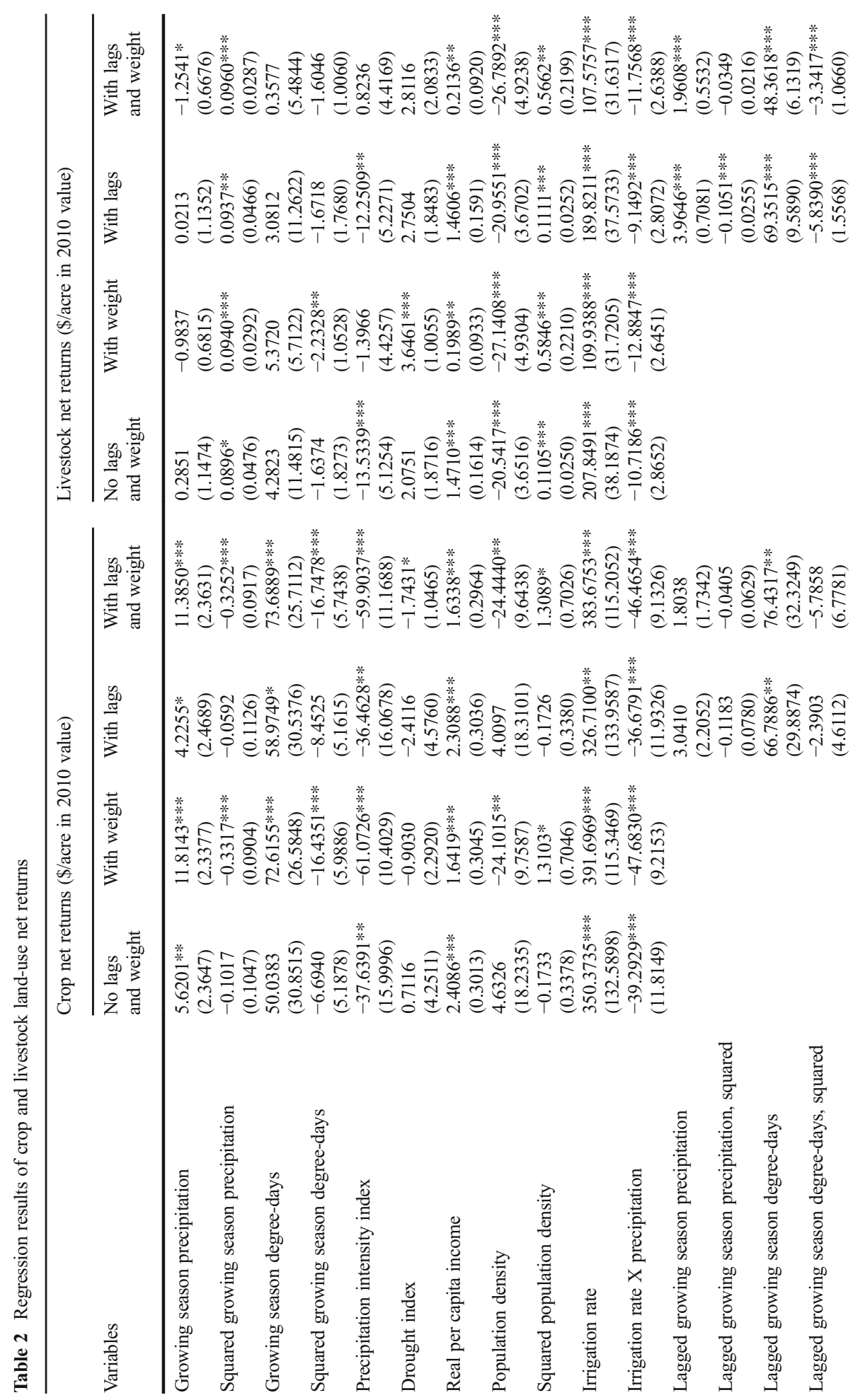




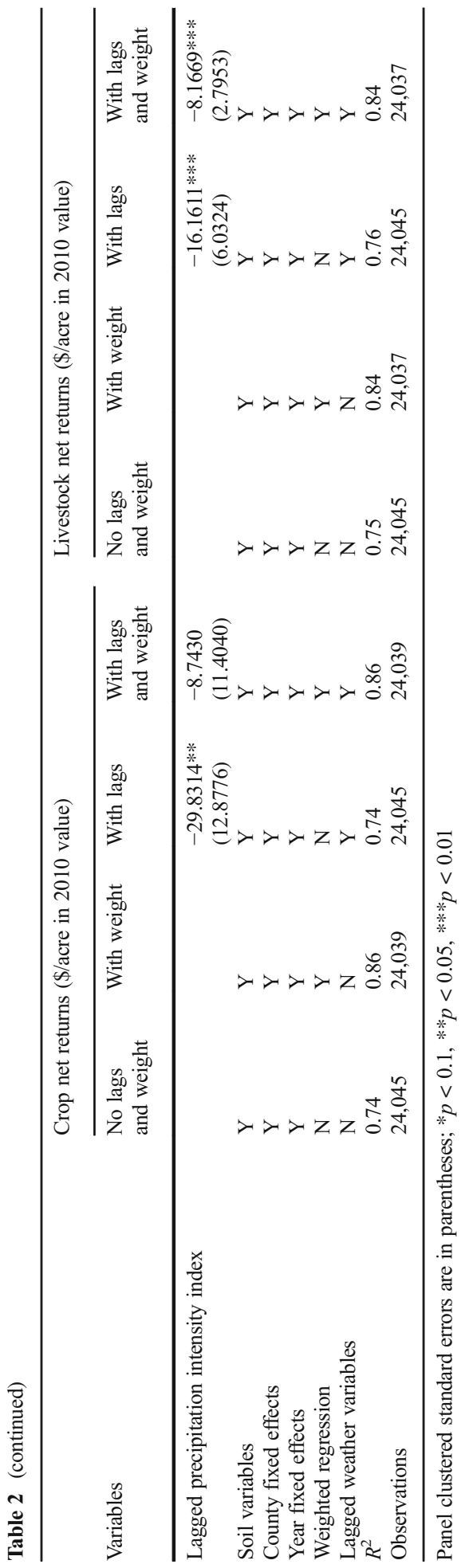




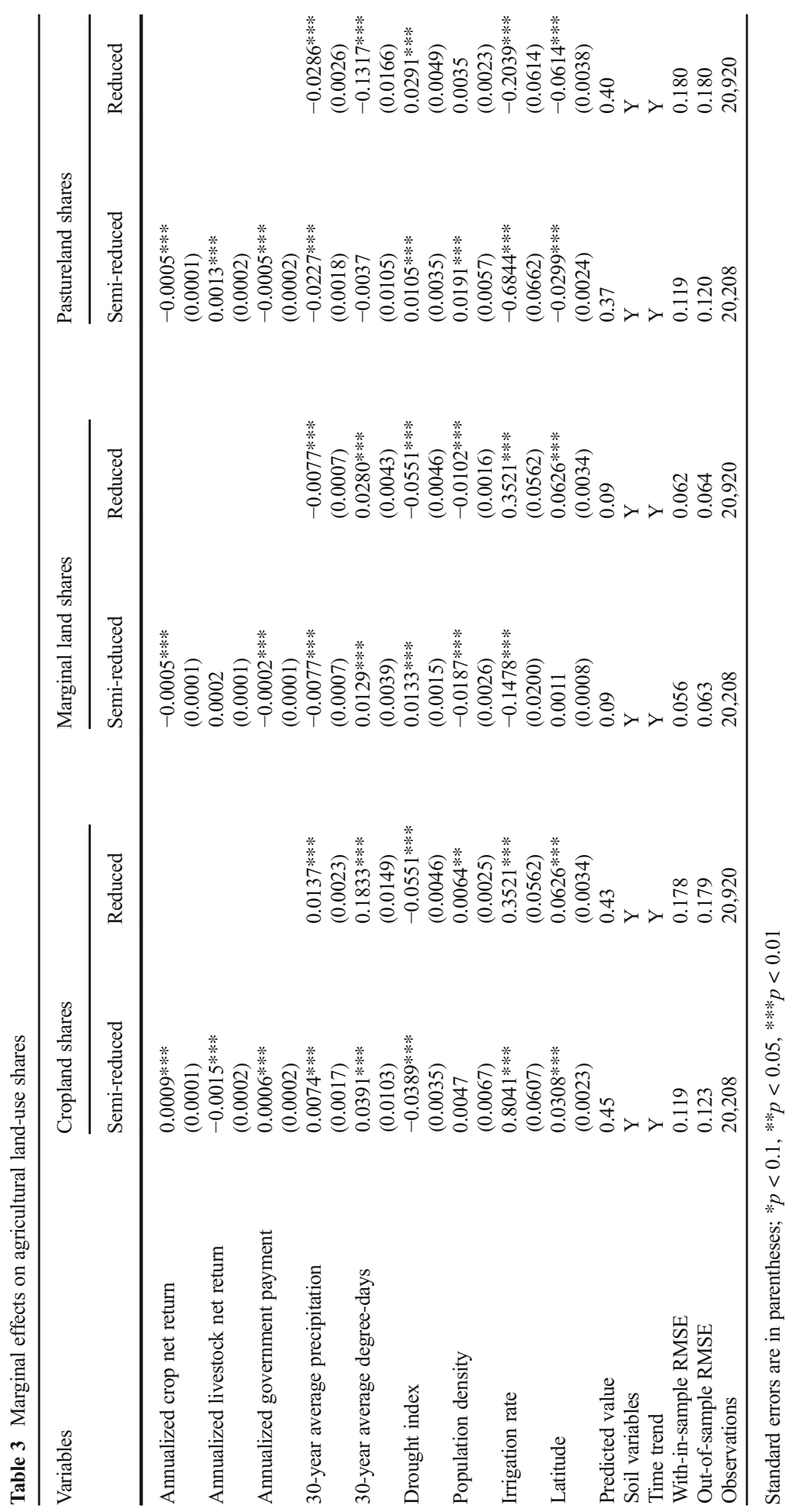


substitution towards more intensive activities such as crop production or livestock grazing on marginal land. Irrigation also has significant effects on crop and livestock production, especially during the summer when water demand is high (Elsner et al. 2010). As expected, the model shows that farmers would put more land in crop production with an increase in available irrigation, because effects from precipitation and drought are potentially mitigated by irrigation technology.

\subsection{Robustness checks}

We test the robustness of the net return model for two purposes. We include lagged weather fluctuation variables to address the concern of the possible endogeneity problem as discussed in Fisher et al. (2012) and Deschênes and Greenstone (2012). We also apply weighted regression to overcome heteroskedasticity. As shown in Table 2, results from different specifications are consistent for both crop and livestock net return regressions. Regardless of the inclusion of lagged weather variables, the weighted regressions give higher values of the goodness-of-fit for both crop and livestock net return estimations. In addition, we test estimation models using different datasets and reported results in Table A1 and A2 in the appendix. For example, we use the growing season from April to September as defined in Deschênes and Greenstone (2007). We also test the sensitivity of livestock net returns to different stocking rate assumptions. Both results are consistent to these in Table 2, suggesting that the selected net return model is robust to different model specifications, functional forms and datasets.

We compare the semi-reduced form land-use model with the reduced-form model to test which model fits the data better (Table 3). Effects of 30-year averaged precipitation are consistent for both models. Compared to the reduced-form land-use model, effects of 30 -year averaged degree-days have smaller magnitudes. We further apply the Wald test of the semi-reduced form model and find that the joint test statistics (the chi-squared value) of annualized net returns, other socio-economic variables and climate variables are $493.79,930.22$ and 2300.29, respectively. Based on the $p$ value, we are able to reject the null hypothesis of no significant effects at the $5 \%$ confidence level. We then compute the with-in- and out-of-sample root-mean-squared-error (RMSE) from two models. Specifically, we run the land-use share model using seven census years and leave one census year for out-of-sample prediction. We choose different census years to leave out, repeat the procedure eight times and then calculate the averaged RMSEs. Both with-in- and outof-sample RMSE from the semi-reduced land-use model have smaller values than that of the reduced one, indicating this model has better predictive capabilities. Thus, the semireduced form model is used to predict land-use change from different climate scenarios, and we prefer this model also because socio-economic variables in the model would help to construct future socio-economic scenarios in the assessment of climate impacts.

\section{Impacts of future climate on agricultural net returns and land-use shares}

\subsection{Changes in agricultural net returns under future climate and SSPs}

Figure 1 shows percent changes of livestock net returns under future climate and SSPs over 2010 to 2099, compared to the historical mean covering 1969 to 2010. There are two important findings in this graph. First, both crop and livestock net returns are increasing over time but have different responses to future climate and socio-economic scenarios. With 

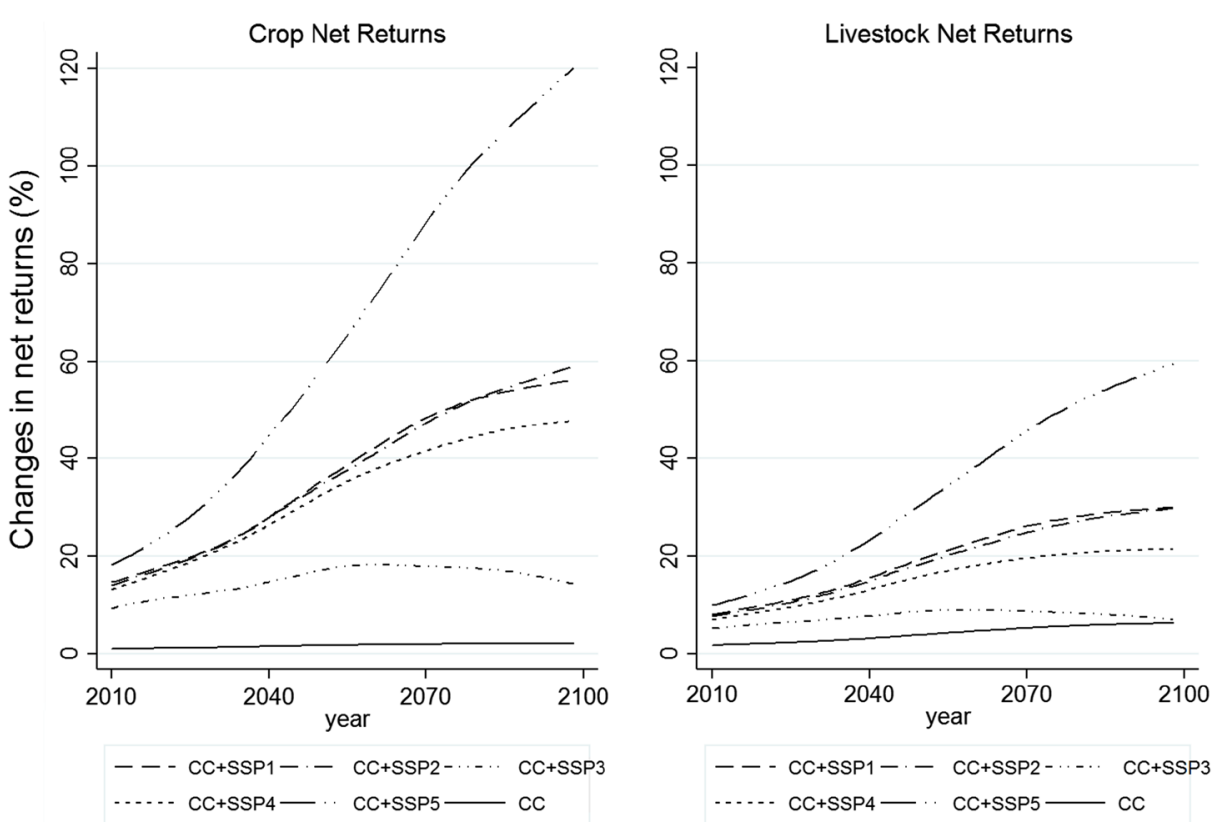

Fig. 1 Percent changes in predicted net returns under future climate and SSPs. Note: all values are averaged across 20 global climate model projections and two emission scenarios. "CC" indicates only future climate impacts; "CC+ SSPX" indicates impacts from both future climate and SSPs. "X" stands for 1 to 5 . All values are compared to the baseline from 1976 to 2005

impacts of future climate only ("CC"), livestock net return has a larger increase rate than crop net return over time. This is possibly because livestock production is more tolerant to heat and wet climate than crop production, thus less affected by warmer climate. However, with impacts of future climate and SSPs ("CC + SSP1" to "CC + SSP5"), crop net return has a larger increase rate than livestock net return over time. This suggests that the change in socio-economic scenarios may overcome some damages from crop failures that are caused by future climate.

Second, larger uncertainty of climate impacts is expected when incorporating SSPs. With impacts from future climate only ("CC") and by the end of the twenty-first century, crop and livestock net returns on average are projected to increase by 2 and $4 \%$ from the historical mean, respectively. This is about an increase of $\$ 2$ per acre above the historical mean crop and livestock net returns. With impacts from future SSPs and climate ("CC + SSP1" to "CC + SSP5"), crop and livestock net returns on average would increase by 38 and $19 \%$ from the historical mean, or about an increase of $\$ 39$ and $\$ 12$ per acre over the historical mean crop and livestock net returns, respectively.

\subsection{Changes in agricultural land uses}

To project land use under future climate and socio-economic scenarios, we first project a baseline covering 1976 to 2005 and then project three future periods: period 2030 covering 2010 to 2039, period 2050 covering 2040 to 2069, and period 2070 covering 2070 to 2099. For each period, we calculate the percent change from the baseline for three alternative cases: 
(1) only allowing climate to change and holding all other variables constant; (2) only allowing socio-economic variables to change and holding all other variables constant; and (3) allowing all variables to change.

\subsubsection{Impacts of future climate}

Figure 2 shows the temporal and spatial distributions of impacts of future climate on agricultural land uses, without the effects of SSPs. In the maps, all changes in land uses are averaged over 20 global climate model projections for two emission scenarios. In the early period (i.e., 2030), magnitudes of land-use changes on average are small, with a small number of counties having land-use changes larger than $10 \%$ or smaller than $-10 \%$. However, there is a large variation of changes in agricultural land uses across counties over time. By the end of the twenty-first century, counties across much of the northern USA and the intermountain western USA show increased cropland, while counties across the southeastern USA show increased pastureland. These results are consistent with projected changes in precipitation and degree-days under the same period, where northern regions will become warmer and wetter, and southern regions will be hotter.

\subsubsection{Impacts of SSPS}

Figure 3 shows impacts of SSPs on agricultural land uses, without effects of future climate. There is not much difference among the five SSPs, thus all changes in the maps are aggregated over five SSPs to show temporal and spatial patterns. In general, cropland increases in most counties in the western USA, and decreases in the southeastern region. Marginal land decreases in the western USA and increases in the northeastern, western coastal and inland Pacific northwestern area. Counties in the southeastern USA have increased pastureland and counties in the western USA have decreased pastureland. As time goes by, more counties in
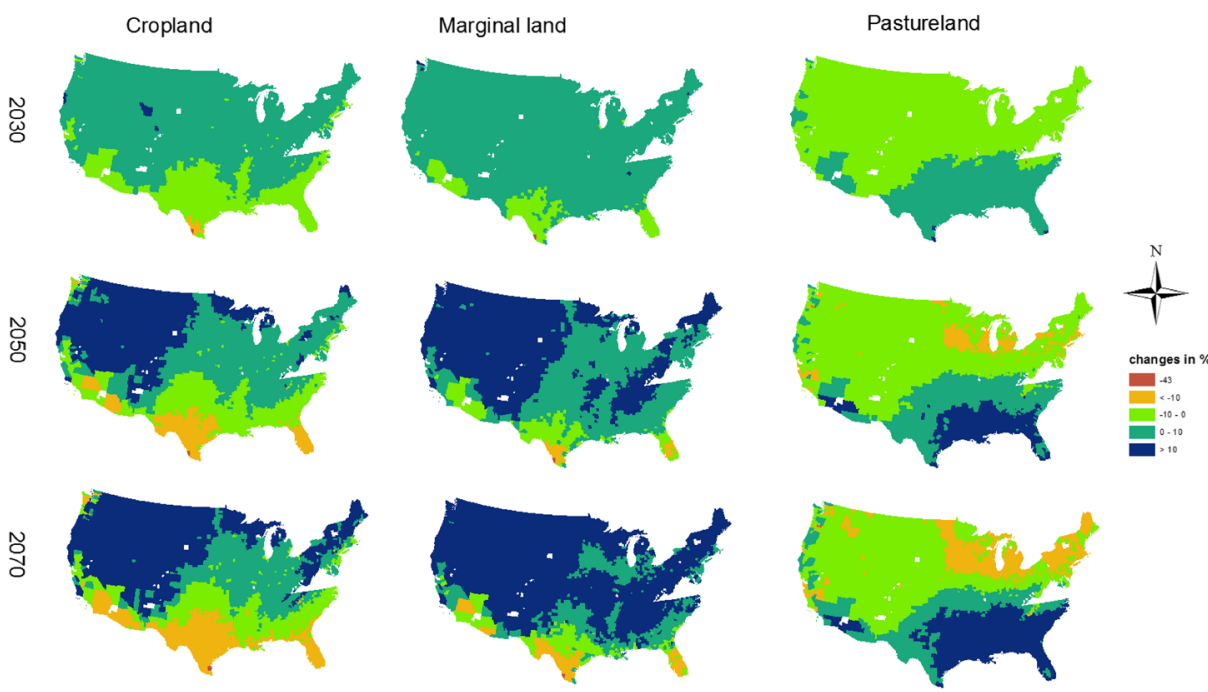

900

1,800
1 3,600 Miles

Fig. 2 Percent changes in agricultural land uses under future climate without SSP. Note: all values are averaged across 20 global climate model projections and two emission scenarios (RCP4.5 and RCP8.5) 

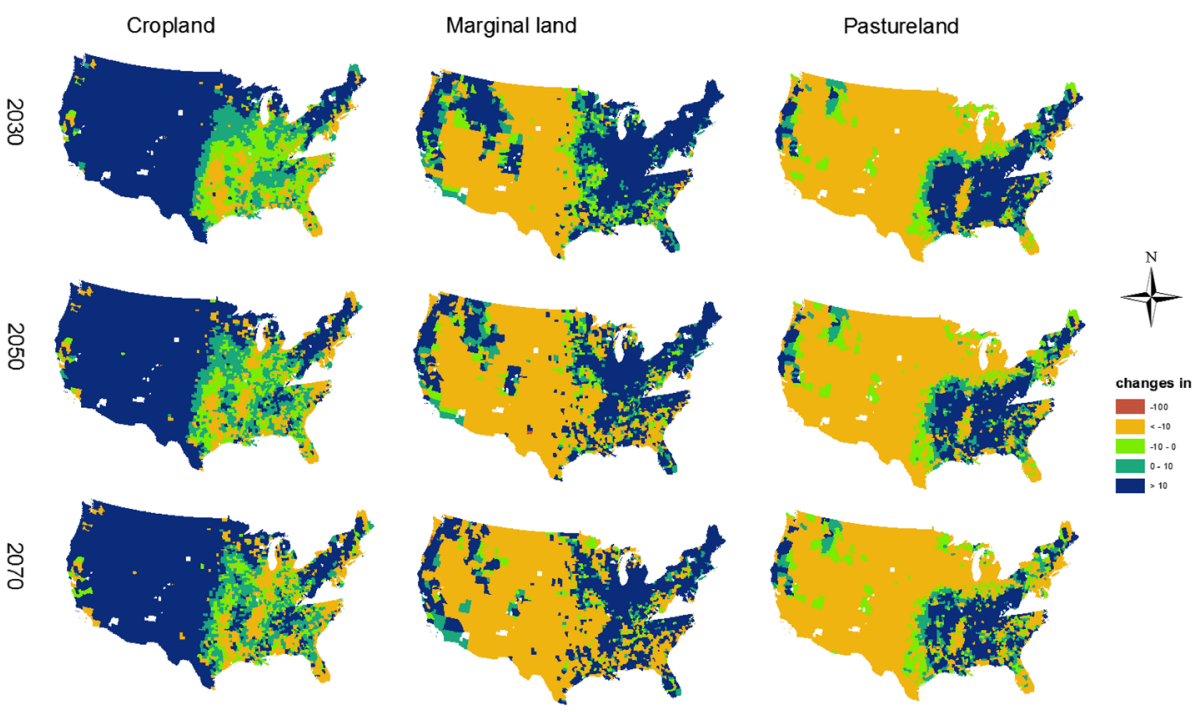
3,600 Mies

Fig. 3 Percent changes in agricultural land uses under SSPs without future climate. Note: changes in agricultural land uses are aggregated across five SSPs

the eastern region have increased cropland and decreased marginal and pastureland. These findings show an increased substitution effect among cropland and other agricultural lands over time. These results are induced by the finding that cropland net returns are predicted to increase at a higher rate than livestock under future SSPs.

\subsubsection{Impacts of future climate and SSPS}

Figure $4 \mathrm{a}, \mathrm{b}$ shows impacts of future climate and SSPs on agricultural land uses for period 2030 and 2070, respectively. For each SSP and agricultural land use, all land-use changes in the maps are averaged over 20 global climate model projections for two emission scenarios. In general, cropland is predicted to increase in most counties under SSPs, with some counties in the southern USA having decreased cropland. Marginal and pastureland decrease in most counties, while some counties in the Midwest area have increased marginal land, and some counties in the southern USA have increased pastureland.

Compared to the early period (i.e., 2030), more counties have increased cropland in the northern USA and more counties have decreased cropland in the southern region by the end of the twenty-first century. Meanwhile, more counties in the southern USA have increased pastureland and more counties in the eastern area have increased marginal land. Compared to Fig. 2 for the same period, climate impacts are offset or even opposite in some counties, suggesting farmers are more active with adaptations through land-use changes under impacts of both future climate and socio-economic scenarios.

Findings from Figs. 2 to 4 indicate that farmers' land-use choices are mainly based on their expectations on market returns, and are less based on their expectations of future climate. While most previous studies have estimated climate impacts in a future world without SSPs (Deschênes and Greenstone 2007, Fezzi and Bateman 2015, Mendelsohn 
(a)
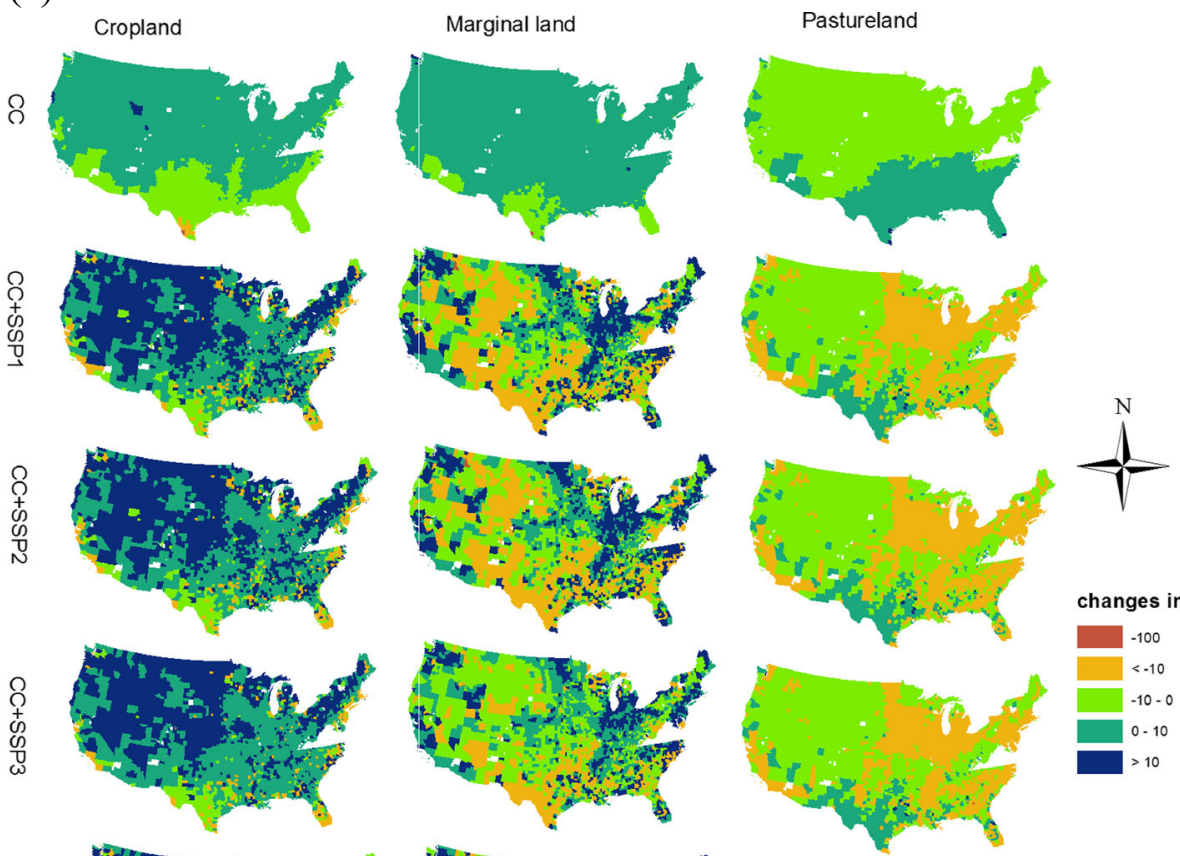

changes in \%
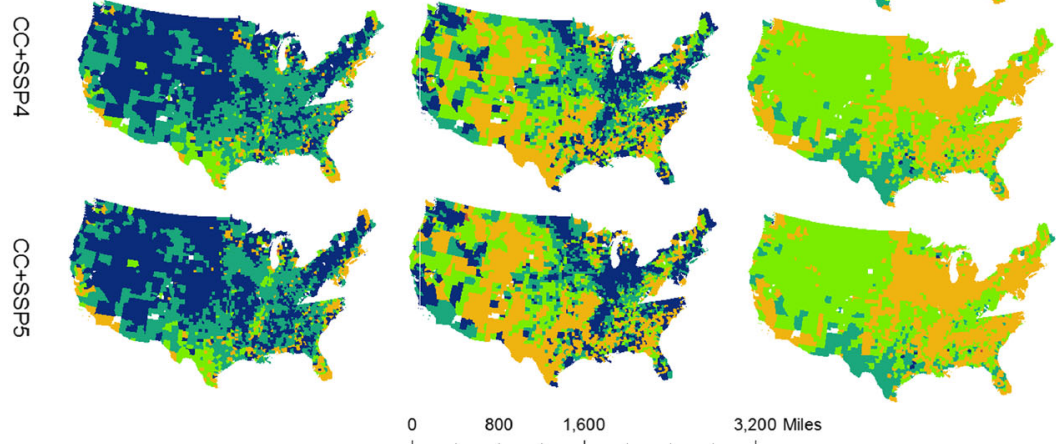

3,200 Miles

Fig. 4 Percent changes in agricultural land uses under future climate and SSPs for 2030 and 2070, respectively. Note: changes in agricultural land uses are aggregated across 20 global climate model projections and two emission scenarios. "CC" indicates only future climate impacts; "CC+ SSPX" indicates impacts from both future climate and SSPs. "X" stands for 1 to 5. All values are compared to the baseline from 1976 to 2005 a Percent changes in agricultural land uses around 2030. b Percent changes in agricultural land uses around 2070

et al. 1994, Mu et al. 2013, Schlenker et al. 2005), we find farmers' adaptation behavior to future climate is substantially different in the future world with SSPs, implying the importance to including socio-economic scenarios in climate impact assessments.

\section{Conclusion and discussion}

In this paper, we apply a two-stage approach to incorporate future socio-economic scenarios into the investigation of climate impacts on agricultural land uses in the USA. We find 
(b)
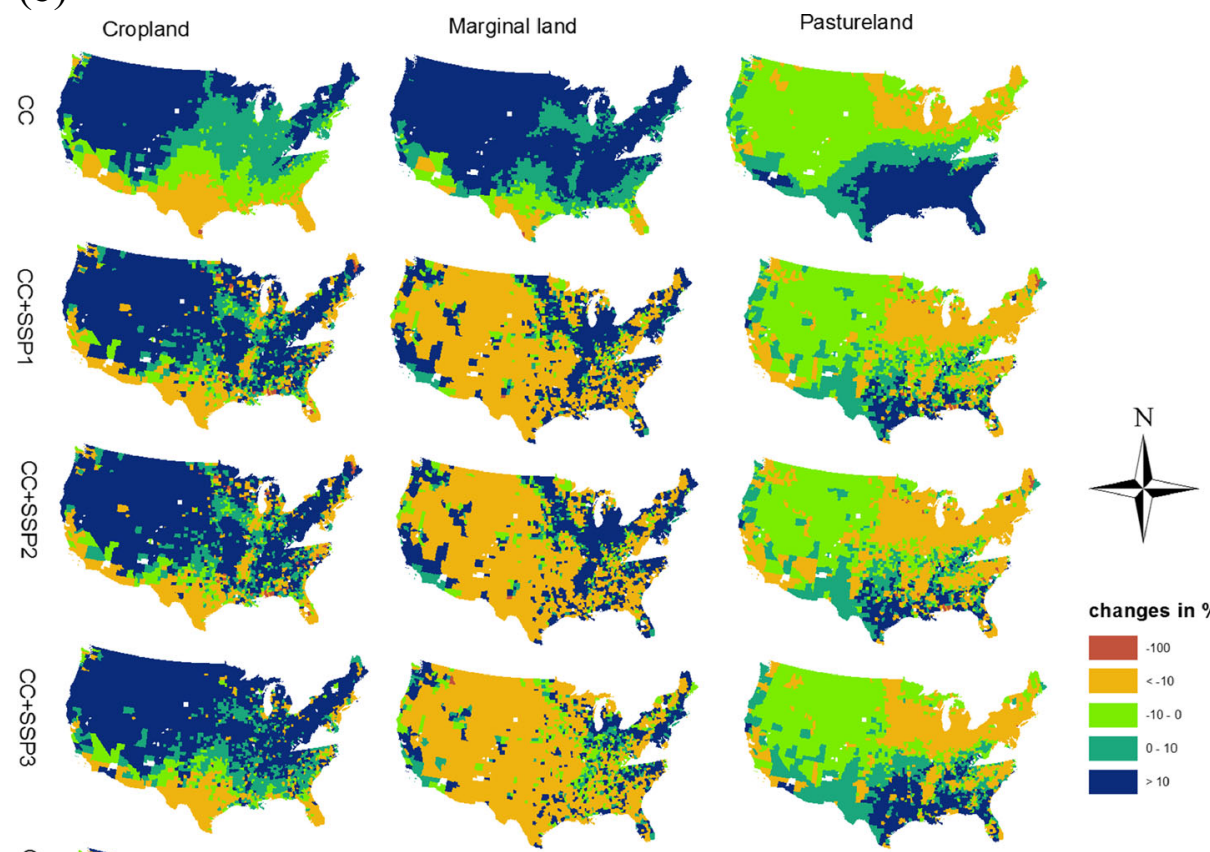

changes in \%
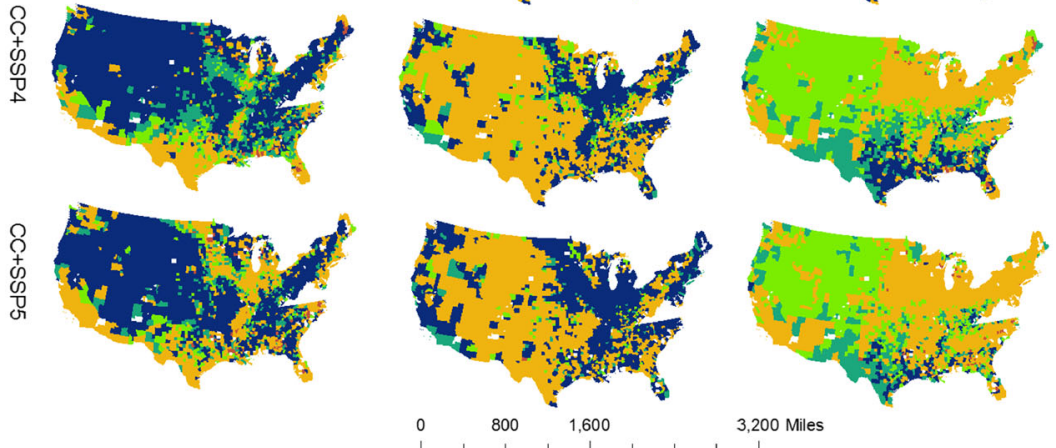

Fig. 4 (continued)

increases in cropland and decreases in marginal and pastureland in the future world. Changes in land uses vary largely due to uncertainty from future socio-economic scenarios. Previous land-use studies have found that farmers' land-use decisions rely on economics and soil qualities, and our results further suggest that land-use net return is the most important factor influencing farmers' land-use decisions under future climate. This finding has implications for policies regarding climate change adaptation and mitigation through agricultural land uses.

From a policy perspective, examining agricultural land-use change in the USA is a significant step in examining potential influences of producing biofuel feedstock on land-use patterns to reduce greenhouse gas (GHG) emissions and to investigate high food prices. For example, use of cropland for biofuel production in the USA will sequester carbon through the growth of the feedstock. However, it does not account for effects caused by higher food prices, to which worldwide farmers respond by converting other lands to cropland (Havlík et al. 2012, 
Searchinger et al. 2008). Future work should involve identifying policies that target shifts in the amount and types of agricultural land and amount of GHG emissions under future climate and socio-economic scenarios.

In this paper, we focus on agricultural land-use changes. However, climate may affect forest and development land uses as well. These may lead to converting land from agricultural production or deforestation to urban uses (Bigelow et al. 2017). Given the different mechanisms for changes in land-use development, such as economic development, increase in per capita income as well as changes in immigration patterns, these are important topics for future research. Moreover, the current analysis does not include price change projections from global models consistent with SSPs. Including price changes could also make the analysis with SSPs very different from ones with only climate change effects.

Acknowledgements The project described in this publication was supported by Grant/Cooperative Agreement Number G14AC00243 from the United States Geological Survey. Its contents are solely the responsibility of the authors and do not necessarily represent the official views of the USGS.

Open Access This article is distributed under the terms of the Creative Commons Attribution 4.0 International License (http://creativecommons.org/licenses/by/4.0/), which permits unrestricted use, distribution, and reproduction in any medium, provided you give appropriate credit to the original author(s) and the source, provide a link to the Creative Commons license, and indicate if changes were made.

\section{References}

Abatzoglou JT (2013) Development of gridded surface meteorological data for ecological applications and modelling. Int J Climatol 33:121-131

Abatzoglou JT, Brown TJ (2012) A comparison of statistical downscaling methods suited for wildfire applications. Int J Climatol 32:772-780

Adams RM et al (1990) Global climate change and US agriculture. Nature 345:219-224

Annan F, Schlenker W (2015) Federal crop insurance and the disincentive to adapt to extreme heat. Am Econ Rev 105:262-266

Antle JM, Capalbo SM (2010) Adaptation of agricultural and food systems to climate change: an economic and policy perspective. Applied Economic Perspectives and Policy 32:386-416

Antle JM et al (2004) Adaptation, spatial heterogeneity, and the vulnerability of agricultural systems to climate change and CO2 fertilization: an integrated assessment approach. Clim Chang 64:289-315

Bigelow DP et al (2017) How does urbanization affect water withdrawals? Insights from an econometric-based landscape simulation. Land Econ 93(3):413-436

Burke $M$ et al (2015) Incorporating climate uncertainty into estimates of climate change impacts. Review of Economics and Statistics 97:461-471

Deschênes O, Greenstone M (2007) The economic impacts of climate change: evidence from agricultural output and random fluctuations in weather. Am Econ Rev 97:354-385

Deschênes O, Greenstone M (2012) The economic impacts of climate change: evidence from agricultural output and random fluctuations in weather: reply. Am Econ Rev 102:3761-3773

Elsner MM et al (2010) Implications of 21st century climate change for the hydrology of Washington state. Clim Chang 102:225-260

Fezzi C, Bateman IJ (2015) The impact of climate change on agriculture: nonlinear effects and aggregation bias in Ricardian models of farm land values. J Assoc Environ Resour Econ 2:57-92

Fisher AC et al (2012) The economic impacts of climate change: evidence from agricultural output and random fluctuations in weather: comment. Am Econ Rev 102:3749-3760

Haim D et al (2011) Climate change and future land use in the United States: an economic approach. Climate Change Economics 02:27-51

Havlík P et al (2012) Crop productivity and the global livestock sector: implications for land use change and greenhouse gas emissions. Am J Agric Econ 95:442-448

Kelly DL, Kolstad CD, Mitchell GT (2005) Adjustment costs from environmental change. J Environ Econ Manag 50:468-495 
Lawler JJ et al (2014) Projected land-use change impacts on ecosystem services in the United States. Proc Natl Acad Sci 111:7492-7497

Lubowski RN, Plantinga AJ, Stavins RN (2006) Land-use change and carbon sinks: econometric estimation of the carbon sequestration supply function. J Environ Econ Manag 51:135-152

Lubowski RN, Plantinga AJ, Stavins RN (2008) What drives land-use change in the United States? A national analysis of landowner decisions. Land Econ 84:529-550

Mendelsohn R, Nordhaus WD, Shaw D (1994) The impact of global warming on agriculture: a Ricardian analysis. Am Econ Rev:753-771

$\mathrm{Mu}$ JE, McCarl BA, Wein AM (2013) Adaptation to climate change: changes in farmland use and stocking rate in the US. Mitig Adapt Strateg Glob Chang 18:713-730

Mu JE, Wein AM, McCarl BA (2015) Land use and management change under climate change adaptation and mitigation strategies: a U.S. case study. Mitig Adapt Strateg Glob Chang 20:1041-1054

O'Neill BC et al (2015) The roads ahead: narratives for shared socioeconomic pathways describing world futures in the 21 st century. Glob Environ Chang 42:169-180

Radeloff V et al (2012) Economic-based projections of future land use in the conterminous United States under alternative policy scenarios. Ecol Appl 22:1036-1049

Reilly J et al (2003) US agriculture and climate change: new results. Clim Chang 57:43-67

Schlenker W, Hanemann WM, Fisher AC (2005) Will US agriculture really benefit from global warming? Accounting for irrigation in the hedonic approach. Am Econ Rev:395-406

Schlenker W, Hanemann WM, Fisher AC (2006) The impact of global warming on US agriculture: an econometric analysis of optimal growing conditions. Rev Econ Stat 88:113-125

Searchinger T et al (2008) Use of US croplands for biofuels increases greenhouse gases through emissions from land-use change. Science 319:1238-1240

Tebaldi C et al (2006) Going to the extremes. Clim Chang 79:185-211

Wooldridge, J.M. 2009. Correlated random effects models with unbalanced panels. Manuscript (version July 2009) Michigan State University

Wu J et al (2004) From microlevel decisions to landscape changes: an assessment of agricultural conservation policies. Am J Agric Econ 86:26-41 